\title{
AChRs Are Essential for the Targeting of Rapsyn to the Postsynaptic Membrane of NMJs in Living Mice
}

\author{
Po-Ju Chen, ${ }^{\star}$ Isabel Martinez-Pena y Valenzuela, ${ }^{\star}$ Mohamed Aittaleb, and Mohammed Akaaboune \\ Department of Molecular, Cellular, and Developmental Biology, University of Michigan, Ann Arbor, Michigan 48109
}

\begin{abstract}
Rapsyn, a $43 \mathrm{kDa}$ scaffold protein, is required for the clustering of acetylcholine receptors (AChRs) at synaptic sites between mammalian motor neurons and muscle cells. However, the mechanism by which rapsyn is inserted and retained at postsynaptic sites at the neuromuscular junction (NMJ) in vivo remains largely unknown. We found that neither the N-terminal myristoylation nor the cysteine-rich RING H2 domain of rapsyn is required for its stable association with the postsynaptic membrane of NMJs. When N-myristoylationdefective rapsyn-EGFP mutant (G2A) and RING-H2 domain truncated rapsyn-EGFP were electroporated into sternomastoid muscles, a strong rapsyn fluorescent signal was observed selectively at synapses, similar to WT rapsyn-EGFP. The targeting of rapsyn-EGFP (WT and mutants) is independent of synaptic activity because they were inserted at denervated NMJs. However, when the coiled-coil domain (the AChR-binding domain of rapsyn) is deleted, rapsyn fails to associate with AChRs at NMJs of living mice. In cultured myoblasts (in which AChRs are absent), myristoylated WT rapsyn mostly localizes to lysosomes and is not associated with the plasma membrane. However, in the presence of AChR subunits, rapsyn molecules were targeted to the cell surface and formed aggregates with AChRs. The targeting of AChRs to the cell membrane, in contrast, does not require rapsyn because expressed AChRs are visible on the cell membranes of rapsyn-deficient myoblasts. These results provide evidence for an active role of AChRs in the targeting of rapsyn to the NMJ in vivo.
\end{abstract}

Key words: AChR; confocal microscope; culture myoblasts; denervation; NMJ; rapsyn

Significance Statement

Rapsyn is required for the clustering of acetylcholine receptors (AChRs) at postsynaptic sites. However, the mechanism by which rapsyn is targeted to synaptic sites at the vertebrate neuromuscular junction remains unclear. In this study, we showed that the coiled-coil domain of rapsyn is required for its targeting to the cell surface via its interaction with AChRs. In contrast, the targeting of AChRs to the cell membrane does not require rapsyn. These results indicate that AChRs play a critical role in the insertion and/or association of rapsyn with the plasma membrane of synaptic sites.

\section{Introduction}

The formation and maintenance of acetylcholine receptor (AChR) clusters in the postsynaptic membrane is the hallmark of a neuromuscular junction (NMJ). The effectiveness of synaptic communication between nerve terminals and postsynaptic cells

Received Dec. 22, 2015; revised March 25, 2016; accepted April 13, 2016.

Author contributions: M. Aittaleb and M. Akaaboune designed research; P.-J.C. and I.M.-P.y.V. performed research; M. Aittaleb contributed unpublished reagents/analytic tools; P.--J.C., I.M.-P.y.V., and M. Akaaboune analyzed data; P.-J.C. and M. Akaaboune wrote the paper.

This work was supported by the National Institutes of Health (Grants NS-047332 and NS-082615 to M. Akaaboune), We thank Drs. Richard Hume and Ryan Insolera (University of Michigan) for critical comments on this manuscript and Akaaboune laboratory members Lyna Azzouz and Bavica Gummadi for technical assistance and comments on this manuscript.

The authors declare no competing financial interests.

*P.-J.C. and I.M.-P.y.V. contributed equally to this work.

Correspondence should be addressed to Dr. Mohammed Akaaboune, Department of Molecular, Cellular, and Developmental Biology, Neuroscience Program, University of Michigan, Ann Arbor, MI 48109. E-mail: makaabou@umich.edu.

DOI:10.1523/JNEUROSCI.4580-15.2016

Copyright $\odot 2016$ the authors $\quad 0270-6474 / 16 / 365680-06 \$ 15.00 / 0$ depends on the stability and the maintenance of a high density of AChRs. Several molecules of the signaling pathway involved in the clustering of AChRs and the formation of NMJs have been identified (Wu et al., 2010). Among these molecules, rapsyn, a 43 $\mathrm{kDa}$ receptor-associated scaffold protein that is enriched at postsynaptic membranes (Porter and Froehner, 1985), is required for the insertion and maintenance of AChR clusters at synaptic sites in an agrin mechanism (Gautam et al., 1995). The exact colocalization of rapsyn and AChRs at the crest of junctional folds of $\mathrm{NMJ}$ in vivo and their precise accumulation at newly formed clusters strongly suggest that the location and function of these proteins may be influenced by each other. Indeed, several studies have shown that rapsyn interacts with the large intracellular loop of all receptor subunits (Miyazawa et al., 1999; Lee et al., 2009) and this interaction is likely to be critical for the localization of both AChRs and rapsyn at the synapse.

In nonmuscle expression systems, functional and structural studies on rapsyn have shown that the $\mathrm{N}$-terminal myristoylation site of rapsyn is required for its targeting to the plasma membrane 
(Phillips et al., 1991b), that the coiled-coil (CC) domain (aa 298 331) is required for its interaction with AChRs, and that the cysteine-rich RING domain (aa 363-402) is required for its interaction with $\beta$-dystroglycan (Bartoli et al., 2001; Ramarao et al., 2001). However, it remains largely unknown whether any of these domains are essential for the targeting of rapsyn to the postsynaptic membrane of NMJs in living mice.

Although it is well documented that rapsyn is essential for the clustering of AChRs on the cell surface of postsynaptic membranes (Gautam et al., 1995), increasing evidence suggests that AChRs control the trafficking and localization of rapsyn at synaptic sites. For instance, in the zebrafish mutant sofa potato, which lacks expression of $\mathrm{AChR}$, rapsyn remains stuck in the Golgi (Park et al., 2012). Similarly, focal dissipation of AChRs from clusters on cultured myotubes by laser illumination prevents the insertion and accumulation of new rapsyn (Bruneau et al., 2008). However, it remains unclear whether AChRs are required for the targeting of rapsyn to synaptic sites in living mice.

In this study, we electroporated rapsyn mutants lacking specific domains into sternomastoid muscles of living mice to test which of functional rapsyn's domains are essential for its targeting and/or association with the plasma membrane at the synapse. We also tested whether the presence of AChRs is required for the rapsyn localization at the cell surface of myoblasts.

\section{Materials and Methods}

Plasmid constructs and reagents. All rapsyn-EGFP constructs (WT, G2A, $\Delta$ RING-H2, and $\Delta \mathrm{CC}$ ) and Lamp1-mCherry were generated in our laboratory as described previously (Aittaleb et al., 2015). All constructs were driven by a CMV promoter. Antibodies were purchased from the Developmental Studies Hybridoma Bank (University of Iowa).

Mice, muscle denervation, plasmid electroporation, AChR labeling, and NMJ imaging. In this study, female non-Swiss albino mice (6-10 weeks old, 20-30 g) were used. The original pairs of the mice were purchased from Harlan Laboratories and bred in an animal facility at the University of Michigan. All animal methods and usage were approved by the University of Michigan Institutional Animal Care and Use Committee.

For denervation or electroporation, adult mice were anesthetized with an intraperitoneal injection of a mixture of $80 \mathrm{mg} / \mathrm{kg}$ ketamine and 20 $\mathrm{mg} / \mathrm{kg}$ xylazine. The denervation of the sternomastoid muscle of mice was performed by excising $\sim 5 \mathrm{~mm}$ of nerve. Innervated and denervated ( $8 \mathrm{~d}$ of denervation) sternomastoid muscles were surgically exposed and rapsyn constructs (WT and mutants, $5 \mu \mathrm{g} / \mu \mathrm{l}$ ) were electroporated as described in our previous studies (Bruneau and Akaaboune, 2010). Seven days after electroporation, NMJs were labeled with $\alpha$-bungarotoxin Alexa Fluor 594 (BTX-Alexa594) and then imaged with a confocal microscope (Leica SP5) as described in our previous work (Martinez-Pena et al., 2015). The $z$-stacks were then collapsed and the contrast adjusted with Adobe Photoshop.

In some experiments, NMJs were imaged with a conventional microscope and the fluorescence intensity of synapses was assayed using a quantitative fluorescence imaging technique, as described previously (Martinez-Pena et al., 2015).

Cell culture, transfection, and cell imaging. C2C12 myoblasts were purchased from the American Type Culture Collection and maintained in DMEM (11995-065; Invitrogen) supplemented with 20\% fetal bovine serum (S11050, Atlanta Biologicals). All cells were grown in the presence of $100 \mathrm{U} / \mathrm{ml}$ penicillin and $100 \mu \mathrm{g} / \mathrm{ml}$ streptomycin at $37^{\circ} \mathrm{C}$, under a humidified atmosphere and $5 \% \mathrm{CO}_{2}$.

The localization of AChRs and rapsyn was performed on C2C12 myoblasts that were cotransfected with rapsyn-EGFP and four subunits of AChRs as described in our previous studies (Aittaleb et al., 2015).

To examine whether the insertion of AChR at the cell surface is independent of rapsyn, myoblast cells deficient in rapsyn (a generous gift from Lin Mei, Georgia Reagents University, GA) were transfected with the four subunits of AChR and then fixed, labeled with Anti-AChR antibody (mAb35) and imaged. Images of fixed and live cells were acquired using a $100 \times$ objective on an inverted Andor/Olympus IX81 spinning disk confocal microscope. The $z$-stacks were performed using the ImageJ software (NIH) and the contrast of images was adjusted with Photoshop.

\section{Results}

Neither the N-terminal myristoylation domain nor the cysteine-rich RING-H2 domain of rapsyn is required for targeting to NMJs in vivo

Previous studies have shown that N-terminal myristoylation, a lipid modification that anchors proteins to membranes, is necessary for the association of rapsyn with the plasma membrane in a nonmuscle expression system (Phillips et al., 1991a; Ramarao and Cohen, 1998). To test whether the N-myristoylation of rapsyn is also essential for its association with AChR clusters at the NMJs of living mice, we electroporated a rapsyn mutant construct (tagged with EGFP) in which a single glycine was changed to alanine $(\mathrm{G} 2 \mathrm{~A})$ to prevent $\mathrm{NH}$-terminal myristoylation. If $\mathrm{N}$-terminal myristoylation is essential for the targeting of rapsyn to synaptic sites, then the rapsyn-G2A mutant should not be present at synaptic clusters. However, $7 \mathrm{~d}$ after electroporation, the NMJs of all muscle cells electroporated with rapsyn G2A mutant showed a strong fluorescence signal that was perfectly colocalized with AChRs as identified by BTX-Alexa594 at synaptic clusters (39 NMJs; six mice; Fig. 1B), suggesting that the NH2terminal myristoylation of glycine 2 is not necessary for the association of rapsyn with the postsynaptic membrane of NMJs. Rapsyn G2A mutant also showed strong GFP fluorescence in the nuclei of electroporated muscles (Fig. $1 B$, asterisks; see Discussion).

Previous studies have shown that the cysteine-rich RING-H2 domain of rapsyn binds to $\beta$-dystroglycan, a component of the dystrophin glycoprotein complex (Bartoli et al., 2001). To test whether the RING-H2 domain is necessary for rapsyn association with the plasma membrane at synaptic sites, the sternomastoid muscle was electroporated with a rapsyn construct ( $\Delta$ RING-H2EGFP) that lacks the RING-H2 domain. As shown in Figure $1 C$, $\Delta$ RING-H2-EGFP fluorescence was observed specifically at synapses and perfectly colocalized with AChRs at the crest of junctional folds on all electroporated muscles (31 NMJs; six mice), indicating that the RING-H2 domain is not required for rapsyn targeting to synaptic sites. Quantification of GFP fluorescence intensity on an arbitrary scale showed no significant difference in levels (mean \pm SEM: WT $=24.4 \pm 4.7,4$ mice; $\mathrm{G} 2 \mathrm{~A}=18.7 \pm$ $3.2,4$ mice, $p=0.366 ; \Delta \mathrm{RING}-\mathrm{H} 2=19.2, \pm 1.9,5$ mice, $p=0.32$; cells expressing high levels of GFP).

\section{Targeting of rapsyn to synapses does not require synaptic activity}

Because neither N-terminal myristoylation nor the RING-H2 domain appeared to be required for targeting rapsyn to synaptic sites, we wondered whether the presence of a factor(s) released from the nerve terminal might play a role. To assess this idea, the sternomastoid muscle was denervated surgically and, $8 \mathrm{~d}$ later, muscles were electroporated with WT or rapsyn-EGFP mutant constructs (G2A-EGFP, rapsyn $\Delta$ RING-H2-GFP). Seven days after electroporation, AChRs were labeled with BTX-Alexa594 and rapsyn fluorescence was examined. We found that both WT rapsyn and the rapsyn mutants colocalized with AChRs at all electroporated denervated NMJs (WT: 29 NMJs, 3 mice; G2A: 8 
A
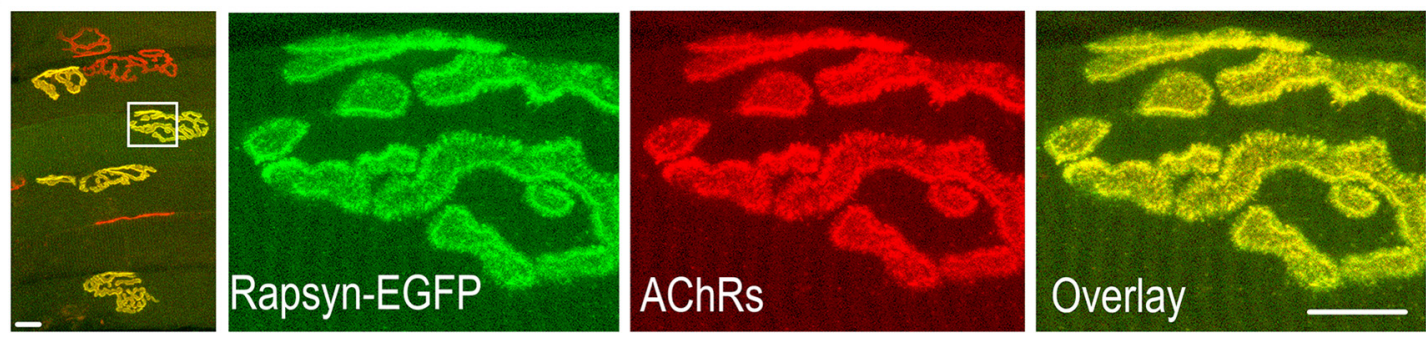

B
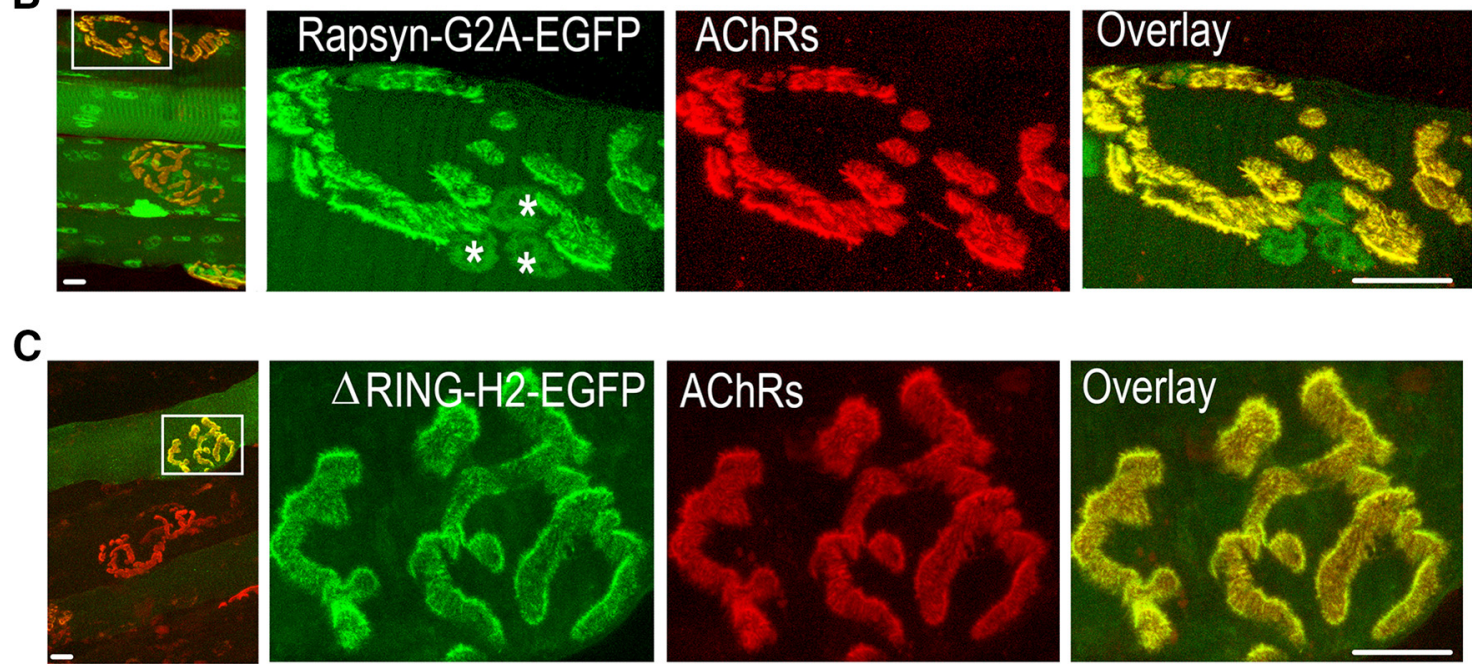

Figure 1. Neither the N-terminal myristoylation site nor the cysteine-rich domain of rapsyn is required for the targeting and association of rapsyn with the plasma membrane at adult NMJ. Sternomastoid muscles were electroporated with WT, mutant G2A rapsyn-EGFP, or $\Delta$ RING-H2-rapsyn-EGFP and, $7 \mathrm{~d}$ later, AChRs were labeled with BTX-Alexa 594, muscles were fixed, and synapses expressing fluorescent rapsyn were imaged with the confocal microscope. A, Representative wide-field view of electroporated muscles with WT rapsyn-EGFP (left). Right, High-power view of the boxed area in the image. $\boldsymbol{B}$, Example of a wide-field view of muscles expressing G2A mutant rapsyn-EGFP (the N-terminal myristoylation site glycine was changed to alanine) and a high-power view of the boxed area; nuclei show also rapsyn fluorescent labeling as indicated by asterisks. C, Example of a wide-field view of muscles expressing rapsyn-EGFP lacking the RING-H2 domain ( $\Delta$ RING-H2-rapsyn-EGFP) and a high-power view of the boxed area. Scale bars, $10 \mu \mathrm{m}$.

NMJs, 3 mice; $\Delta$ RING-H2: 11 NMJs, 3 mice) (Fig. 2). The rapsyn G2A mutant also accumulated in the nucleus of denervated muscles. These results showed that the association of rapsyn with the postsynaptic plasma membrane does not require nerve-derived factors or nerveevoked muscle activity.

CC domain is essential for targeting of rapsyn to synaptic sites

Previous studies have shown that the CC domain was required for rapsyn interaction with AChRs (Ramarao et al., 2001). To test whether this interaction is relevant for the targeting and/or retaining rapsyn at the synaptic plasma membrane, a rapsyn mutant in which the CC domain was deleted (rapsyn $\Delta$ CC-EGFP) was electroporated into sternomastoid muscles. In contrast to the synaptic localization of WT, G2A, and $\triangle$ RINGH2-GFP rapsyn, we found that the lack of CC domain resulted in a complete loss of the exogenous rapsyn localization to synaptic sites of both denervated $(\mathrm{NMJ}=16,3$ mice) and innervated $(\mathrm{NMJ}=15,3$ mice $)$ muscles. Instead, the CC rapsyn mutant-EGFP exhibited a diffuse distribution throughout the entire innervated and denervated muscle fibers (Fig. $3 A$ ). The absence of
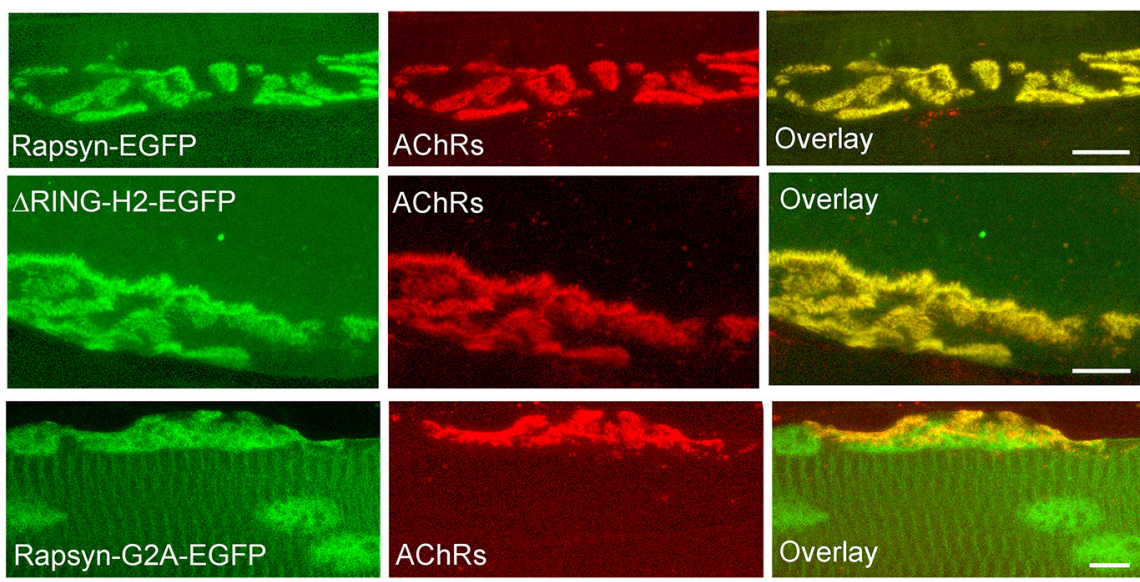

Figure 2. Lack of synaptic activity had no effect on the targeting of rapsyn. Denervated sternomastoid muscles (8d) of adult mice were electroporated with WT rapsyn-EGFP, G2A rapsyn-EGFP, or $\triangle$ RING-H2 rapsyn-EGFP. Seven days after electroporation, AChRs were labeled with BTX-Alexa594 (red) to identify synapses, fixed, and imaged. Shown are examples of NMJs expressing WT rapsyn-EGFP (top), $\triangle$ RING-H2 rapsyn-EGFP (middle), and G2A-rapsyn-EGFP (bottom). Scale bars, $10 \mu \mathrm{m}$.

the CC rapsyn mutant at synapses also rules out the possible association between exogenous and endogenous rapsyn through their TPR domains. These results indicate that the targeting and association of rapsyn with the plasma membrane of synaptic sites required $\mathrm{CC}$ domains and are possibly mediated by an interaction with AChR. 
A
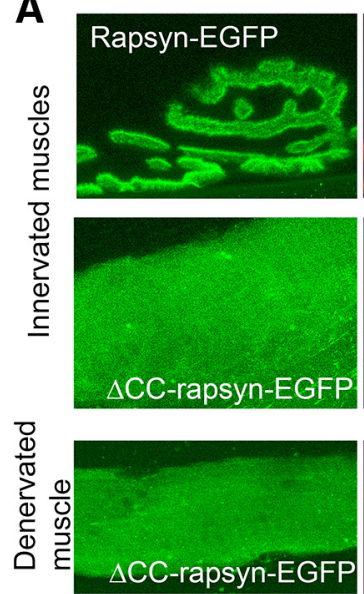
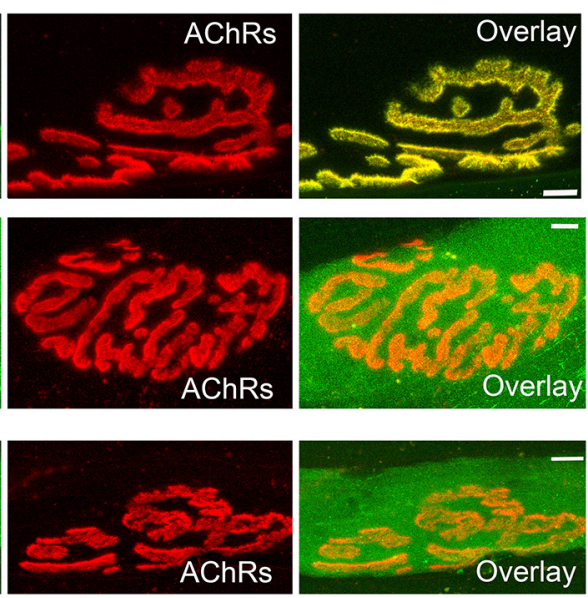

B

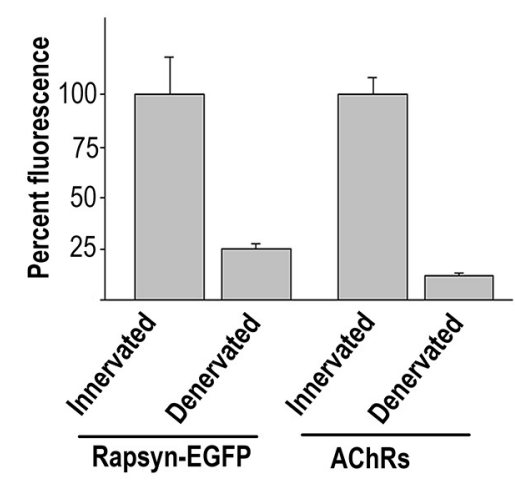

Figure 3. The CC domain is required for the targeting of rapsyn to synaptic sites. The sternomastoid muscles of adult innervated and denervated mice were electroporated with rapsyn-EGFP lacking the CC domain (rapsyn $\Delta C$ C-EGFP). At $7 \mathrm{~d}$ after electroporation, AChRs were labeled with a saturating dose of BTX-Alexa594 and superficial synapses on electroporated (green) muscle fibers were imaged and then fixed and imaged. $A$, Examples of innervated NMJs on muscle expressing WT (top) and $\Delta C$ C-rapsyn-EGFP (middle). Bottom, Rapsyn $\Delta$ CC-EGFP expression in denervated muscles. Note that the rapsyn mutant fails to express at both innervated and denervated NMJs compared with WT rapsyn. $B$, Graph summarizing the mean \pm SD percentage of fluorescence intensity of labeled AChRs and rapsyn-EGFP at innervated and denervated NMJs $(p<0.001)$. Scale bars, $10 \mu \mathrm{m}$.

To further delineate the relationship of rapsyn and AChRs, we investigated whether the density of rapsyn changes proportionally when the density of AChR is altered. This was examined by measuring fluorescently labeled AChRs and fluorescent rapsynGFP at NMJs of denervated muscles, in which the density of AChR decreases significantly upon denervation (Bruneau and Akaaboune, 2006). Quantification of fluorescence intensity of labeled rapsyn and AChRs at NMJs denervated for $15 \mathrm{~d}$ showed that AChR and rapsyn declined to similar extents (76\% decrease in rapsyn and $88 \%$ decrease in AChR; Fig. 3B), indicating that the number/density of rapsyn at synaptic sites is closely associated with the number/density of AChRs.

\section{AChRs are essential for rapsyn association with the plasma membrane}

If AChRs are involved directly in targeting rapsyn to the plasma membrane of muscle cells, then cotransfecting AChRs along with rapsyn should promote the targeting of rapsyn to the cell surface. To test this idea, muscle precursor cells (myoblasts) that do not express AChRs at this stage of development (Aittaleb et al., 2015) were transfected with either WT rapsyn-EGFP and LAMP-1mcherry to make lysosomes visible or cotransfected with rapsynEGFP and the four subunits of adult mouse AChR. In myoblasts transfected with WT rapsyn-EGFP without AChR subunits, after $24 \mathrm{~h}$, we found that rapsyn was mainly localized to Lamp-1positive lysosomes in the juxtanuclear region as marked by antiLamp1 and that there was little or no fluorescent rapsyn signal associated with the plasma membrane (Fig. 4A,C), consistent with our previous results (Aittaleb et al., 2015). In contrast, when myoblasts were cotransfected with rapsyn-EGFP and AChR subunits and cells were fixed without permeabilization to show only surface AChRs (Fig. 4B), rapsyn-EGFP was mostly associated with AChRs at the cell surface (yellow and orange in the merged image), but there also were some regions of densely clustered rapsyn without overlying AChRs located inside the cell (green in the merged, collapsed image).

Next, we investigated whether rapsyn promotes the targeting of AChRs at areas rich in rapsyn. If rapsyn is involved in AChR targeting, then we would expect to see the presence of AChRs wherever rapsyn is clustered, particularly in lysosomes at the jux- tanuclear region rich in rapsyn (Aittaleb et al., 2015). To test this, myoblast cells were cotransfected with four AChR subunits and rapsyn-EGFP and, $24 \mathrm{~h}$ later, cells were fixed, permeabilized, and immunostained with anti-AChR antibody (mAb35) so that both surface and intracellular receptors were labeled. As shown in Figure $4 C$, rapsyn-EGFP was mostly associated with AChRs at surface clusters and intracellular puncta of various size and shape. However, there were regions of highly clustered rapsyn-GFP (green in the merge) that did not show any overlap with AChRs and were localized to lysosomes in the juxtanuclear regions (Fig. $4 C$, purple arrows). In an additional experiment, myoblasts from mice carrying a null mutation for rapsyn were transfected with the four AChR subunits and, 24 h later, cells were fixed without permeabilization and then stained with BTX-Alexa488 to label surface AChRs. Figure $4 D$ shows that, in rapsyn ${ }^{-1-}$ myoblasts, there is extensive surface labeling of AChRs on the cell surface, indicating that rapsyn is not required for the targeting of AChRs to the myoblast cell surface.

\section{Discussion}

Many lines of evidence indicate that the presence of rapsyn on the plasma membrane is essential for the clustering of AChRs. Most importantly, there is a failure of AChR cluster formation in muscle cells deficient in rapsyn (Gautam et al., 1995). Previous work and the current study have suggested that the relationship between rapsyn and AChRs can be reciprocal. For instance, decreased rapsyn expression at the synapse was observed in mice deficient in an AChR subunit (Witzemann et al., 1996; Schwarz et al., 2000) and the density of rapsyn is reduced significantly in mice deficient in $\alpha$-syntrophin and $\alpha$-dystrobrevin, which exhibit a dramatic reduction in total AChR levels compared with WT (Adams et al., 2000; Grady et al., 2000). Our other previous results suggested that that AChRs are required for the maintenance of rapsyn density at receptor clusters on the cell surface of cultured myotubes (Bruneau et al., 2008).

This study provides the first evidence that AChRs are essential for localizing rapsyn to synapses in adult mouse muscle by interacting with the rapsyn CC domain. Specifically, we showed that: (1) electroporation of rapsyn mutants that lack either the $\mathrm{N}$-terminal myristoylation or RING-H2 domains are expressed 
A 등
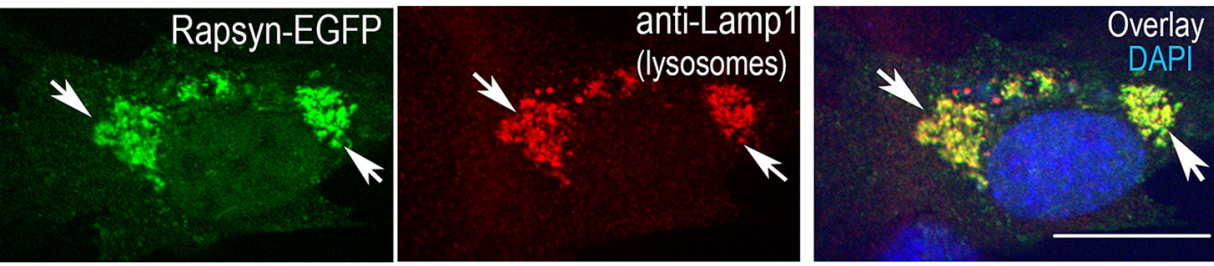

B
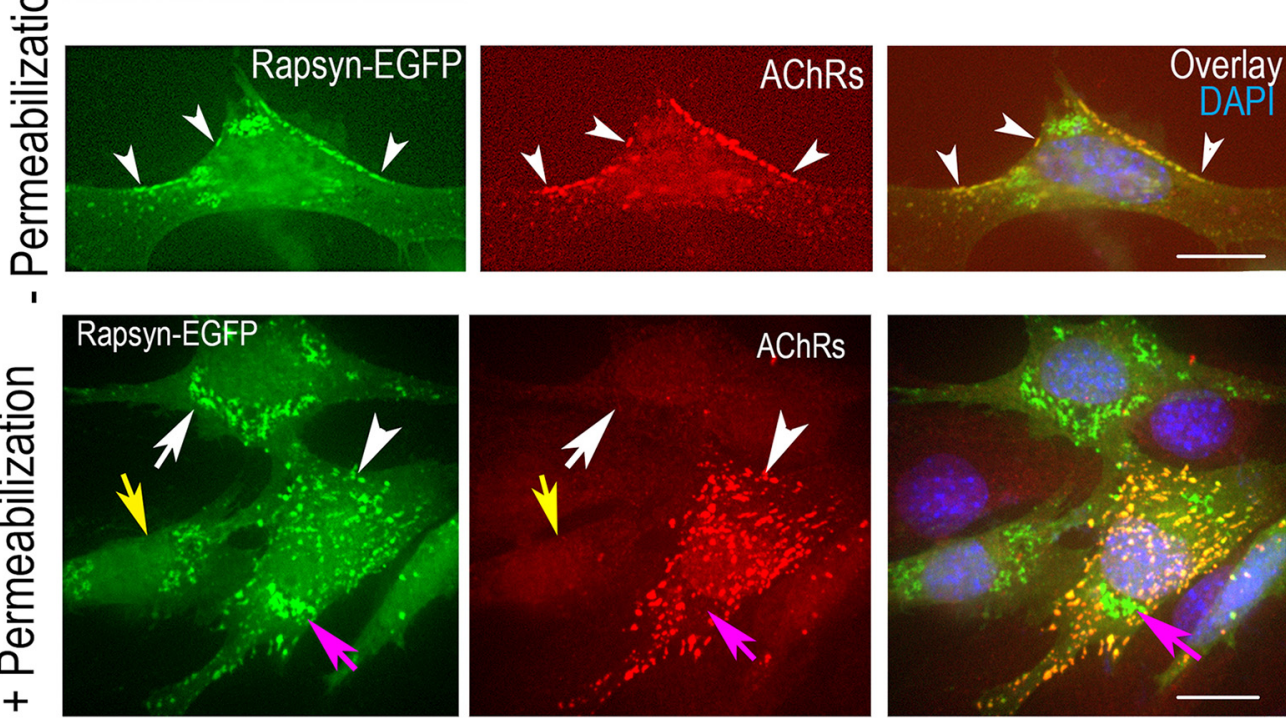

$\mathrm{C}$
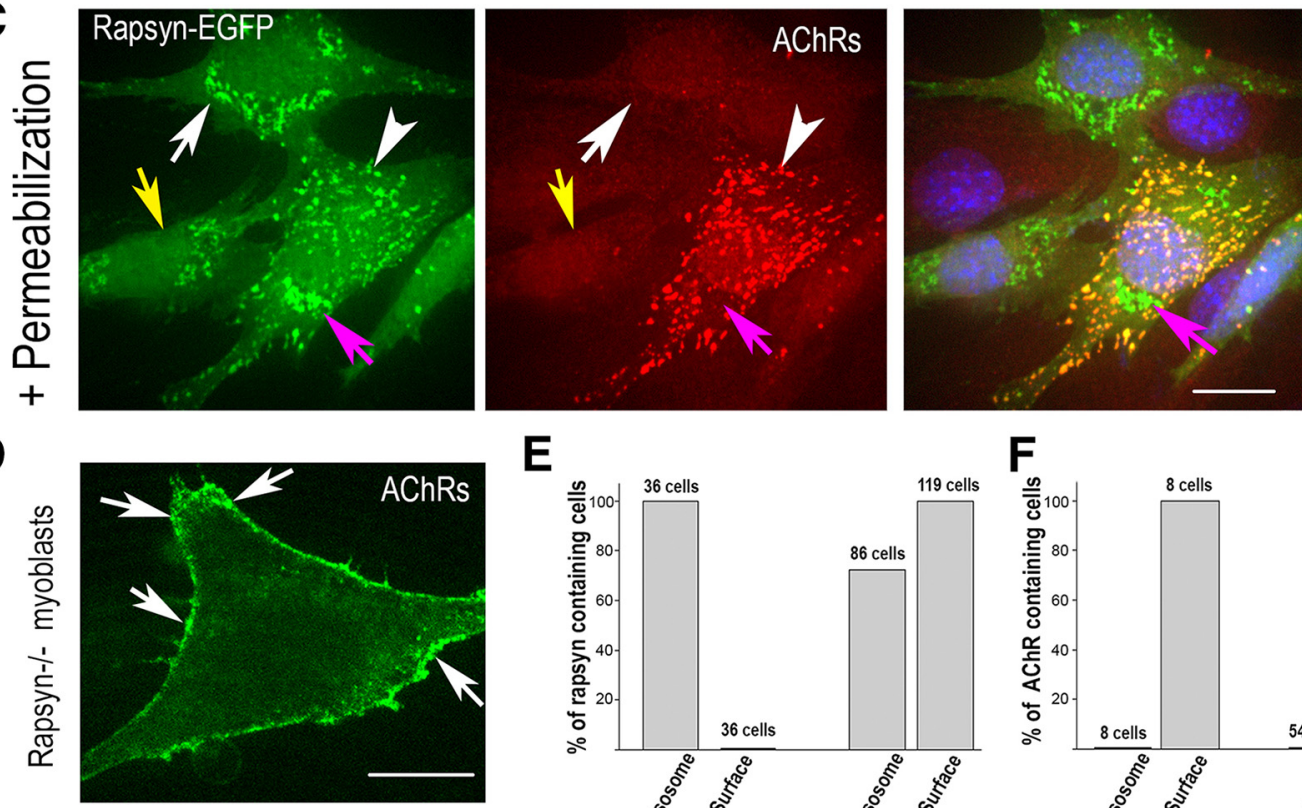

E
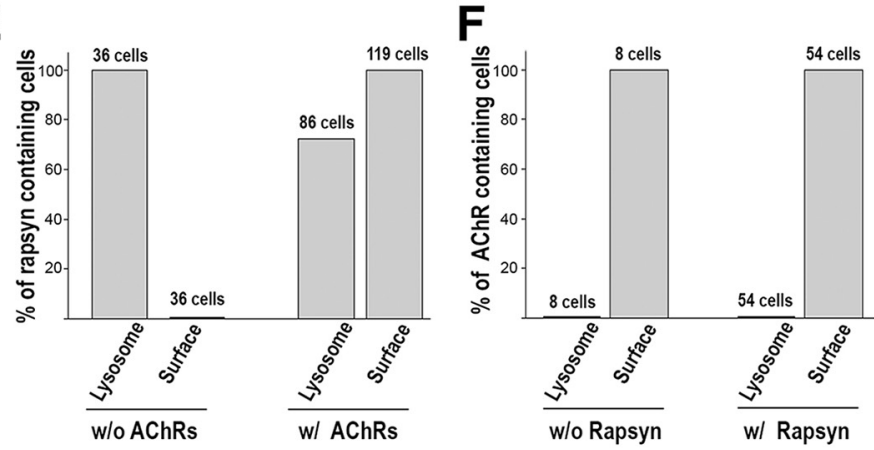

Figure 4. AChRs are required for accumulating rapsyn on the cell surface. 22 C12 myoblasts or myoblasts deficient in rapsyn were transfected with rapsyn-EGFP alone, rapsyn-EGFP and the four subunits of AChRs, or AChR subunits alone. After $24 \mathrm{~h}$, cells were fixed and imaged using the confocal spinning disk microscope. $A$, Representative images of $C 2 C 12$ myoblasts transfected with rapsyn-EGFP, fixed, permeabilized, and immunostained with rat anti-Lamp1 are shown. Note that most of rapsyn-EGFP colocalizes with lysosomes (arrows) (Aittaleb et al., 2015) and there is a complete absence of rapsyn association with plasma membrane. $B$, Example images of $(2 C 12$ myoblasts cotransfected with rapsyn-EGFP and $A C h R \alpha, A C h R \beta, A C h R \delta$, and $A C h R \varepsilon$ subunits, fixed without permeabilization and stained with AChR antibody (to label only surface receptors). Arrowheads show AChRs and rapsyn coclusters at the cell surface. C, Cells were permeabilized with $1 \%$ Triton and immunostained with AChR antibody to label AChRs on the surface and inside the cell. Note that there is no colocalization of intracellular AChRs with rapsyn in lysosomes (purple arrows). Arrowheads show the colocalization of rapsyn and AChRs. In the absence of AChRs, rapsyn is mainly concentrated in the lysosomes (white arrows) and is not associated with plasma membrane (yellow arrows). D, Myoblasts deficient in rapsyn were transfected with AChR four subunits alone and surface receptors were labeled with BTX-Alexa488. E, Myoblasts were cotransfected with rapsyn-EGFP and lamp1-mcherry with or without four subunits of AChRs. F, Myoblasts were cotransfected with four subunits of AChRs and lamp1-mcherry with or without rapsyn-GFP. Twenty-four hours after transfection, cells were fixed with or without permeabilization, stained with anti-AChR antibody, and imaged. Graphs in $\boldsymbol{E}$ and $\boldsymbol{F}$ show quantifications of percentage of cells containing rapsyn and AChRs on cell surface and lysosomes, respectively. Scale bars, $10 \mu \mathrm{m}$.

selectively at synaptic sites, where they perfectly colocalize with AChRs at NMJs in vivo; (2) the specific localization of exogenous rapsyn to synaptic sites is completely lost when the rapsyn CC domain (known to bind AChRs in vitro) is deleted; (3) the association of WT rapsyn with the synaptic plasma membrane is not dependent on synaptic activity, as evidenced by the presence of a rapsyn signal at surgically denervated NMJs; (4) in the myoblast cell line $\mathrm{C} 2 \mathrm{C} 12$ (at a stage of development when AChRs are not yet expressed), when rapsyn is expressed, most of the WT rapsyn colocalizes with lysosomes in the juxtanuclear region and rapsyn has no clear association with the plasma membrane; and (5) however, when rapsyn was coexpressed in $\mathrm{C} 2 \mathrm{C} 12$ cells with AChRs, both molecules were found predominately at the cell surface. Altogether, these results strongly suggest that AChRs serve as a mediator for the targeting and association of rapsyn with the postsynaptic membrane at synaptic sites.

Several studies have shown that myristoylation of proteins serves to target them to the plasma membrane (Pellman et al., 1985; Rein et al., 1986). In nonmuscle cells, the NH2-terminal myristoylation of rapsyn plays an important role for its association with the plasma membrane (Phillips et al., 1991a). However, the specific colocalization of G2A rapsyn-EGFP mutant with AChRs at crests of junctional folds of NMJs of living mice is strong evidence that the $\mathrm{N}$-terminal myristoylation domain is not 
essential for membrane targeting of rapsyn in adult muscle (Fig. $1 B)$. Interestingly, the G2A rapsyn mutant also accumulated in the nucleus. It is unclear how the loss of $\mathrm{N}$-terminal myristoylation allows the translocation of rapsyn to the nucleus. One possibility is that lack of myristoylation results in protein misfolding that uncovers a normally hidden nuclear import signal. Another possibility is that the mutant rapsyn folds normally, but myristoylation prevents nuclear import. Regardless of the mechanism, the nuclear localization raises the possibility that, under some conditions, rapsyn regulates gene expression, so further exploration of the nuclear role of rapsyn would be of interest. It is noteworthy that rapsyn mutations have been shown to be associated with the development of congenital myasthenia syndrome, which varies in both pathology and severity (Engel, 2012).

The current experiments suggest that the association of rapsyn with the plasma membrane of adult muscle does not require nervederived factors or muscle activity because, in denervated muscles, WT and mutant rapsyn ( $\Delta$ RING-H2 or G2A) still localized to the AChR clusters of denervated NMJs (Fig. 2). The denervation experiments thus suggest that, under these conditions, the targeting of rapsyn to synaptic sites is mediated by other postsynaptic proteins. One possibility was $\beta$-dystroglycan because, in nonmuscle cells, it has been reported that rapsyn clusters $\beta$-dystroglycan (a molecule of the dystrophin glycoprotein complex) through its association with the cysteine-rich RING-H2 domain (Bartoli et al., 2001). However, in living mice, it appears that deletion of the RING-H2 domain has no effect on rapsyn targeting because its deletion did not prevent rapsyn's association with the plasma membrane at synaptic sites (Fig. 1C), arguing against the involvement of the dystrophin glycoprotein complex in the targeting of rapsyn at synaptic sites despite their presence in the same intracellular vesicular transport (Marchand et al., 2001). As noted above, another strong candidate involved in localizing rapsyn is the AChR itself. In zebrafish, animals carrying a null mutant for AChR fail to localize rapsyn at synapses and expression of muscle type AChR in zebrafish mutant muscle cells restores the synaptic localization of rapsyn (Ono et al., 2004). Furthermore, AChRs have been shown to enable the transport of rapsyn from the Golgi complex to the plasma membrane (Park et al., 2012). It is also possible that the interaction of rapsyn with calpain, which inhibits its activity and thus allows the stabilization of AChR clusters at the synapse, might contribute to the regulatory mechanism of AChR insertion (Chen et al., 2007). In summary, the present experiments are the first to show that, in mammals, the postsynaptic membrane localization of rapsyn involves AChRs. However, it is not clear whether AChRs are the only molecules that target or retain rapsyn to synaptic sites in vivo.

\section{References}

Adams ME, Kramarcy N, Krall SP, Rossi SG, Rotundo RL, Sealock R, Froehner SC (2000) Absence of alpha-syntrophin leads to structurally aberrant neuromuscular synapses deficient in utrophin. J Cell Biol 150: 1385-1398. CrossRef Medline

Aittaleb M, Chen PJ, Akaaboune M (2015) Failure of lysosome clustering and positioning in the juxtanuclear region in cells deficient in rapsyn. J Cell Sci 128:3744-3756. CrossRef Medline

Bartoli M, Ramarao MK, Cohen JB (2001) Interactions of the rapsyn RING-H2 domain with dystroglycan. J Biol Chem 276:24911-24917. CrossRef Medline

Bruneau EG, Akaaboune M (2006) The dynamics of recycled acetylcholine receptors at the neuromuscular junction in vivo. Development 133:44854493. CrossRef Medline

Bruneau EG, Akaaboune M (2010) Dynamics of the rapsyn scaffolding protein at the neuromuscular junction of live mice. J Neurosci 30:614-619. CrossRef Medline
Bruneau EG, Brenner DS, Kuwada JY, Akaaboune M (2008) Acetylcholine receptor clustering is required for the accumulation and maintenance of scaffolding proteins. Curr Biol 18:109-115. CrossRef Medline

Chen F, Qian L, Yang ZH, Huang Y, Ngo ST, Ruan NJ, Wang J, Schneider C, Noakes PG, Ding YQ, Mei L, Luo ZG (2007) Rapsyn interaction with calpain stabilizes AChR clusters at the neuromuscular junction. Neuron 55:247-260. CrossRef Medline

Engel AG (2012) Current status of the congenital myasthenic syndromes. Neuromuscul Disord 22:99-111. CrossRef Medline

Gautam M, Noakes PG, Mudd J, Nichol M, Chu GC, Sanes JR, Merlie JP (1995) Failure of postsynaptic specialization to develop at neuromuscular-junctions of rapsyn-deficient mice. Nature 377:232-236. CrossRef Medline

Grady RM, Zhou H, Cunningham JM, Henry MD, Campbell KP, Sanes JR (2000) Maturation and maintenance of the neuromuscular synapse: genetic evidence for roles of the dystrophin-glycoprotein complex. Neuron 25:279-293. CrossRef Medline

Lee Y, Rudell J, Ferns M (2009) Rapsyn interacts with the muscle acetylcholine receptor via alpha-helical domains in the alpha, beta, and epsilon subunit intracellular loops. Neuroscience 163:222-232. CrossRef Medline

Marchand S, Stetzkowski-Marden F, Cartaud J (2001) Differential targeting of components of the dystrophin complex to the postsynaptic membrane. Eur J Neurosci 13:221-229. Medline

Martinez-Pena Y, Valenzuela I, Aittaleb M, Chen PJ, Akaaboune M (2015) The knockdown of alphakap alters the postsynaptic apparatus of neuromuscular junctions in living mice. J Neurosci 35:5118-5127. CrossRef Medline

Miyazawa A, Fujiyoshi Y, Stowell M, Unwin N (1999) Nicotinic acetylcholine receptor at 4.6 angstrom resolution: transverse tunnels in the channel wall. J Mol Biol 288:765-786. CrossRef Medline

Ono F, Mandel G, Brehm P (2004) Acetylcholine receptors direct rapsyn clusters to the neuromuscular synapse in zebrafish. J Neurosci 24:54755481. CrossRef Medline

Park JY, Ikeda H, Ikenaga T, Ono F (2012) Acetylcholine receptors enable the transport of rapsyn from the Golgi complex to the plasma membrane. J Neurosci 32:7356-7363. CrossRef Medline

Pellman D, Garber EA, Cross FR, Hanafusa H (1985) Fine structural mapping of a critical NH2-terminal region of p60src. Proc Natl Acad Sci U S A 82:1623-1627. CrossRef Medline

Phillips WD, Maimone MM, Merlie JP (1991a) Mutagenesis of the 43-kd postsynaptic protein defines domains involved in plasma-membrane targeting and Achr clustering. J Cell Biol 115:1713-1723. CrossRef Medline

Phillips WD, Kopta C, Blount P, Gardner PD, Steinbach JH, Merlie JP (1991b) Ach receptor rich membrane domains organized in fibroblasts by recombinant 43-kildalton protein. Science 251:568-570. CrossRef Medline

Porter S, Froehner SC (1985) Interaction of the 43K protein with components of Torpedo postsynaptic membranes. Biochemistry 24:425-432. CrossRef Medline

Ramarao MK, Cohen JB (1998) Mechanism of nicotinic acetylcholine receptor cluster formation by rapsyn. Proc Natl Acad Sci. USA 95:40074012. Medline

Ramarao MK, Bianchetta MJ, Lanken J, Cohen JB (2001) Role of rapsyn tetratricopeptide repeat and coiled-coil domains in self-association and nicotinic acetylcholine receptor clustering. J Biol Chem 276:7475-7483. CrossRef Medline

Rein A, McClure MR, Rice NR, Luftig RB, Schultz AM (1986) Myristylation site in Pr65gag is essential for virus particle formation by Moloney Murine Leukemia-Virus. Proc Natl Acad Sci U S A 83:7246-7250. CrossRef Medline

Schwarz H, Giese G, Müller H, Koenen M, Witzemann V (2000) Different functions of fetal and adult AChR subtypes for the formation and maintenance of neuromuscular synapses revealed in epsilon-subunit-deficient mice. Eur J Neurosci 12:3107-3116. CrossRef Medline

Witzemann V, Schwarz H, Koenen M, Berberich C, Villarroel A, Wernig A, Brenner HR, Sakmann B (1996) Acetylcholine receptor epsilon-subunit deletion causes muscle weakness and atrophy in juvenile and adult mice. Proc Natl Acad Sci U S A 93:13286-13291. CrossRef Medline

Wu H, Xiong WC, Mei L (2010) To build a synapse: signaling pathways in neuromuscular junction assembly. Development 137:1017-1033. CrossRef Medline 